\title{
The effects of feeding time on milk production, total-tract digestibility, and daily rhythms of feeding behavior and plasma metabolites and hormones in dairy cows
}

\author{
M. Niu, ${ }^{1}$ Y. Ying, P. A. Bartell, and K. J. Harvatine ${ }^{2}$ \\ Department of Animal Science, Penn State University, University Park, PA16802
}

\begin{abstract}
The timing of feed intake entrains circadian rhythms regulated by internal clocks in many mammals. The objective of this study was to determine if the timing of feeding entrains daily rhythms in dairy cows. Nine Holstein cows were used in a replicated $3 \times 3$ Latin square design with 14-d periods. An automated system recorded the timing of feed intake over the last $7 \mathrm{~d}$ of each period. Treatments were feeding $1 \times / \mathrm{d}$ at $0830 \mathrm{~h}(\mathrm{AM})$ or $2030 \mathrm{~h}(\mathrm{PM})$ and feeding $2 \times / \mathrm{d}$ in equal amounts at 0830 and $2030 \mathrm{~h}$. All treatments were fed at $110 \%$ of daily intake. Cows were milked $2 \times / d$ at 0500 and $1700 \mathrm{~h}$. Milk yield and composition were not changed by treatment. Daily intake did not differ, but twice-daily feeding tended to decrease total-tract digestibility of organic matter and neutral detergent fiber (NDF). A treatment by time of day interaction was observed for feeding behavior. The amount of feed consumed in the first $2 \mathrm{~h}$ after feeding was $70 \%$ greater for PM compared with AM feeding. A low rate of intake overnight (2400 to $0500 \mathrm{~h} ; 2.2 \pm 0.74 \%$ daily intake/h, mean $\pm \mathrm{SD}$ ) and a moderate rate of intake in the afternoon (1200 to $1700 \mathrm{~h} ; 4.8 \pm 1.1 \%$ daily intake/h) was noted for all treatments, although PM slightly reduced the rate during the afternoon period compared with AM. A treatment by time of day interaction was seen for fecal NDF and indigestible NDF (iNDF) concentration, blood urea nitrogen, plasma glucose and insulin concentrations, body temperature, and lying behavior. Specifically, insulin increased and glucose decreased more after evening feeding than after morning feeding. A cosine function within a 24 -h period was used to characterize daily rhythms using a random regression. Rate of feed intake during spontaneous feeding, fecal NDF and iNDF concentration, plasma glucose, insulin, NEFA, body temperature, and lying behavior fit
\end{abstract}

\footnotetext{
Received April 21, 2014.

Accepted September 2, 2014.

${ }^{1}$ Current address: Department of Animal Science, University of California, Davis.

${ }^{2}$ Corresponding author: kjh182@psu.edu
}

a cosine function within a 24 -h period that was modified by treatment. In conclusion, feeding time can reset the daily rhythms of feeding and lying behavior, core body temperature, fecal NDF and iNDF concentration, and plasma blood urea nitrogen, glucose, and insulin concentration of dairy cows, but has no effect on daily DMI and milk production.

Key words: circadian rhythm, feed intake, dairy cow

\section{INTRODUCTION}

Circadian rhythms are approximately 24 -h repeating cycles followed by most physiological functions in mammals (reviewed by Bass, 2012). Daily rhythmicity is well recognized in dairy cows, and Giannetto and Picciano (2009b) reported that 12 of 25 variables investigated followed a circadian pattern. Briefly, rhythmic changes in plasma insulin, BUN, growth hormone concentration (Lefcourt et al., 1995), body temperature (Lefcourt et al., 1999), and locomotor activities (Giannetto and Picciano, 2009b) have been reported.

Circadian rhythms are entrained by numerous environmental cues, but the light-dark cycle and feed availability are dominant factors (reviewed by Asher and Schibler, 2011). Circadian rhythms also persist in the absence of environmental cues, as they are the product of time-keeping mechanisms present in the central nervous system and most peripheral tissues, although this is difficult to test in lactating cows. Circadian rhythms are adaptive, as they coordinate physiological processes with rhythmic changes occurring in the environment and asynchrony of rhythms have been reported to be detrimental to health and well-being (reviewed by Bass, 2012).

Feed intake is an important consideration in dairy cows, as milk production creates a high energy demand and energy intake can limit milk production. The daily pattern of feed intake is classically described with the majority of feed consumed between sunrise and sunset (e.g., Ray and Roubicek, 1971). Recent work using automated feed-observation systems have reported an active feeding period during the day and a less-active feeding period at night (e.g., DeVries et al., 2003; DeVries and 
von Keyserlingk, 2005). Additionally, the daily patterns of peripheral blood hormones and metabolites change in response to diet (e.g., Oba and Allen, 2003), and the concentration of ruminal AA, ammonia nitrogen, and VFA are responsive to change in feeding time (Robinson et al., 1997, 2002). More recently, Nikkhah et al. (2008) reported that offering feed once a day at $2100 \mathrm{~h}$ altered the daily patterns of plasma metabolites compared with feeding cows at $0900 \mathrm{~h}$.

Entrainment of circadian rhythms by the timing of feed availability is well established in other mammals (reviewed by Asher and Schibler, 2011), but has not been well described in dairy cows. We hypothesized changing feeding time would shift the daily pattern of feeding behavior, which will modify rumen fermentation and shift the daily rhythms of plasma metabolites and hormones. Additionally, we hypothesized that the daily rhythm of body temperature, which is highly regulated by lighting through the central master clock, and lying behavior would not be as responsive to changes in feeding time. The objectives of the current study were to determine the effect of feeding time on milk production and daily behavioral and physiological rhythms. Additionally, total-tract digestibility, milk trans FA profile, and the daily rhythm of fecal NDF and iNDF concentration were used to indirectly observe the effect of treatments on rumen function.

\section{MATERIALS AND METHODS}

\section{Experimental Design and Treatments}

The experiment was conducted from February to March of 2012 at the Pennsylvania State University Dairy Production Research and Teaching Center. Nine multiparous Holstein cows $(109 \pm 31$ DIM; mean \pm $\mathrm{SD})$ were housed in single-rail tiestalls with mattresses and sawdust bedding and randomly assigned to treatment sequences in a replicated $3 \times 3$ Latin square design with 14-d periods. Circadian rhythms normally entrain within $7 \mathrm{~d}$, allowing the use of short observation periods. Lights were out from 2300 to $0500 \mathrm{~h}$ each day and a data-logging device (HOBO Pendant Temp/ Light; Onset Computer Corp., Bourne, MA) verified that the lighting schedule was maintained and observed that the facility averaged $11.7^{\circ} \mathrm{C}$ during the experiment. Cows were individually fed the same diet, which contained $29.7 \% \mathrm{NDF}$ and $17.9 \% \mathrm{CP}$ (Table 1). Treatments were feeding $1 \times / \mathrm{d}$ at $0830 \mathrm{~h}(\mathbf{A M})$ or $2030 \mathrm{~h}$ $(\mathbf{P M})$ or feeding $2 \times / \mathrm{d}$ in equal amounts at 0830 and $2030 \mathrm{~h}$ (AMPM). All treatments were fed ad libitum at $110 \%$ of previous daily intakes and the TMR was mixed immediately before each feeding. Refused feed was removed and weighed before feed delivery in the
Table 1. Ingredient and chemical composition of the experimental diet

\begin{tabular}{|c|c|}
\hline Item & Value $^{1}$ \\
\hline \multicolumn{2}{|l|}{ Ingredient ( $\%$ of $\mathrm{DM})$} \\
\hline Corn silage 2 & 41.4 \\
\hline Alfalfa haylage ${ }^{3}$ & 13.8 \\
\hline Canola meal & 9.5 \\
\hline Roasted soybeans & 9.3 \\
\hline Ground corn & 7.7 \\
\hline Grass hay ${ }^{4}$ & 4.9 \\
\hline Cookie meal & 4.3 \\
\hline Molasses & 3.9 \\
\hline Mineral and vitamin $\operatorname{mix}^{5}$ & 2.8 \\
\hline Cottonseed hulls & 2.2 \\
\hline NPN supplement ${ }^{6}$ & 0.4 \\
\hline \multicolumn{2}{|c|}{ Chemical composition $^{7}$ ( $\%$ of DM) } \\
\hline $\mathrm{CP}$ & 17.9 \\
\hline NDF & 29.7 \\
\hline $\mathrm{ADF}$ & 20.1 \\
\hline Starch & 25.0 \\
\hline Ash & 6.3 \\
\hline
\end{tabular}

${ }^{1}$ All cows were fed the same diet.

${ }^{2}$ Contained $38 \% \mathrm{DM}$ and $8.4 \% \mathrm{CP}, 34.1 \% \mathrm{NDF}$, and $38 \%$ starch on a DM basis.

${ }^{3}$ Contained $48.3 \% \mathrm{DM}$ and $23.4 \% \mathrm{CP}, 38.5 \% \mathrm{NDF}$, and $1.3 \%$ starch on a DM basis.

${ }^{4}$ Contained $88.8 \% \mathrm{DM}$ and $10.3 \% \mathrm{CP}, 66.4 \% \mathrm{NDF}$, and $3.8 \%$ starch on a DM basis.

${ }^{5}$ Vitamin and mineral mix contained (as-fed basis): $45.8 \%$ dried corn distillers grains with solubles: $35.8 \%$ limestone (38\% Ca): $8.3 \%$ magnesium oxide $(54 \% \mathrm{Mg}) ; 6.4 \%$ salt; $1.73 \%$ vitamin $\mathrm{ADE}$ premix; $1.09 \%$ selenium premix $(0.06 \%$ selenium $)$; and $0.88 \%$ trace mineral mix. Composition (DM basis): $11 \%$ CP; $18 \%$ NDF; $5.2 \%$ fat; $14.9 \%$ Ca; $0.35 \% \mathrm{P} ; 4.58 \% \mathrm{Mg} ; 0.41 \% \mathrm{~K} ; 0.31 \% \mathrm{~S} ; 357 \mathrm{mg} / \mathrm{kg}$ of $\mathrm{Cu} ; 1,085 \mathrm{mg} /$ $\mathrm{kg}$ of $\mathrm{Zn} ; 181 \mathrm{mg} / \mathrm{kg}$ of Fe; $6.67 \mathrm{mg} / \mathrm{kg}$ of Se; $125,875 \mathrm{IU} / \mathrm{kg}$ of vitamin A (retinyl acetate); 31,418 IU $/ \mathrm{kg}$ of vitamin D (Activated 7-dehydrocholesterol); and $946 \mathrm{IU} / \mathrm{kg}$ of vitamin $\mathrm{E}$ (DL- $\alpha$ tocopheryl acetate).

${ }^{6}$ Controlled-release urea (Optigen; Alltech Inc., Lexington, KY; $278 \%$ $\mathrm{CP}$ on DM basis).

${ }^{7} \mathrm{n}=3$.

morning for AM and AMPM treatments and at night for the PM treatment.

\section{Data and Sample Collection and Analysis}

Cows were housed in a feed intake observation system similar to Dado and Allen (1993). Briefly, hanging feed tubes were suspended from an electronic load cell wired to a data acquisition system (RLWS 920i; Rice Lake Weighing System, Rice Lake, WI). Feed weight was recorded every $8 \mathrm{~s}$ from d 8 to 14 of each period. The number, size, and intermeal interval of meals were determined by an algorithm developed in IGOR (WaveMetrics Inc., Lake Oswego, OR; algorithm provided by M.S. Allen, Michigan State University, East Lansing) according to Harvatine and Allen (2006). Feed intake across the day was calculated over 30-min and 2-h intervals. Raw data were smoothed by averaging over 180 $\mathrm{s}$ and the rate of feed intake (percent of daily intake 
per hour) was calculated every $8 \mathrm{~s}$ over 10 -min intervals and averaged over reported intervals. As offering fresh feed stimulated feeding, the first $2 \mathrm{~h}$ after each feeding were considered conditioned feeding and were therefore excluded from rhythm analysis. Feed intake at other times was considered spontaneous feeding controlled by hunger, satiety, and internal rhythms.

Total mixed rations and individual feed ingredients were sampled on d 8, 11, and 14, and orts (12.5\%) were sampled from d 8 to 14 of each period. Feed and orts samples were composited by period. Concentrate ingredients were composited based on their diet inclusion rate and analyzed as a single mix. Forages and concentrate mixes were analyzed for DM, ash, starch, and $\mathrm{CP}$ by wet chemistry procedures (Table 1), and orts samples were analyzed for DM, NDF, and ash as described by Rico and Harvatine (2013).

Cows were milked twice daily at 0500 and $1700 \mathrm{~h}$ and milk yield was determined by an integrated milk meter (AfiMilk, SAE Afikim, Israel). Milk was sampled at all milkings on $\mathrm{d} 13$ and 14 of each period and stored at $4^{\circ} \mathrm{C}$ with preservative (Bronolab-WII) until analyzed for fat (Filter B) and true protein by infrared spectroscopy [Fossomatic 4000 Milko-Scan and 400 Fossomatic, Foss Electric, Hillerød, Denmark; AOAC (2000) method 972.160; Dairy One Lab, State College, PA]. An additional milk sample was collected at each milking on d 14, centrifuged at $3,500 \times g$ at $4^{\circ} \mathrm{C}$ for 15 min, and the resulting fat cake was stored at $-20^{\circ} \mathrm{C}$ until analyzed for FA composition according to Rico and Harvatine (2013).

Blood samples were collected from the tail vein 6 times over d 12 through 14 of each period (0330, 0630, 1030, 1530, 1830, and $2230 \mathrm{~h}$ ) using potassium EDTA vacuum tubes (Greiner Bio-One North America Inc., Monroe, NC) to represent approximately every $4 \mathrm{~h}$ of a day. Plasma was harvested, stored, and analyzed for insulin, glucose, BUN, and NEFA as described by Rottman et al. (2014).

Fecal samples were also collected at the same time as blood sampling. Fecal NDF and 240 -h in vitro indigestible NDF (iNDF) were measured at each time point according to Van Soest et al. (1991) and Raffrenato and Van Amburgh (2010), respectively (Cumberland Valley Analytical Services Inc., Maugansville, MD). Second, in situ iNDF was determined for feed ingredients and composited fecal samples using a 12-d ruminal incubation in filter bags (F57; Ankom Technology, Macedon, NY) suspended in a net bag and was used to determine apparent total-tract digestibility as described by Huhtanen et al. (1994).

Core temperature was recorded every $10 \mathrm{~min}$ on d 8 to 14 of each period using an intravaginal temperature probe as an indication of the central circadian rhythm, as body temperature is highly controlled by the master clock in the brain. A miniature plastic-coated temperature recording device (iBCod; Alpha Mach Inc., MontSt.-Hilaire, Canada; Hasselberg et al., 2013) was fastened to a progesterone-free Eazi-Breed CIDR (Pfizer Animal Health, New York, NY). Temperature probes were placed centrally in the vagina using a controlled internal drug release insertion device. Raw data were averaged over the reported intervals.

Lying behavior was determined by a data logging accelerometer (HOBO Onset Pendant G, 64k, Onset Computer Corporation), similar to Ledgerwood et al. (2010), as an observation of an additional behavior rhythm to compare with changes in the rhythm of feeding behavior. Briefly, the $\mathrm{x}, \mathrm{y}$, and $\mathrm{z}$ axes were recorded at 32 -s intervals from d 8 to 14 of each period. An algorithm developed in IGOR (WaveMetrics Inc. USA, Portland, OR) was used to determine lying and standing according to validated parameters (Ledgerwood et al., 2010). The proportion of time spent lying was calculated over the reported intervals.

\section{Statistical Analysis}

Milk yield and composition at each milking, plasma hormone and metabolite concentration, feeding behavior, lying behavior, and body temperature averaged over 2-h intervals, and fecal NDF and iNDF data were statistically analyzed as a replicated design using the MIXED procedure of SAS with repeated measures (version 9.3, SAS Institute Inc., Cary, NC). The model was

$$
\begin{gathered}
\mathrm{Y}_{\mathrm{ijklm}}=\mu+\mathrm{S}_{\mathrm{i}}+\mathrm{P}_{\mathrm{j}}+\mathrm{C}_{\mathrm{k}}\left(\mathrm{S}_{\mathrm{i}}\right)+\mathrm{T}_{1} \\
+\mathrm{H}_{\mathrm{m}}+\mathrm{T}_{\mathrm{l}} \times \mathrm{H}_{\mathrm{m}}+\mathrm{e}_{\mathrm{ijk} \mathrm{k} l},
\end{gathered}
$$

where $Y_{\mathrm{ijklm}}$ is the variable of interest, $\mu$ is the overall mean, $\mathrm{S}_{\mathrm{i}}$ is the random effect of sequence ( $\mathrm{i}=1$ to 6$), \mathrm{P}_{\mathrm{j}}$ is the random effect of period ( $\mathrm{j}=1$ to 3$), \mathrm{C}_{\mathrm{k}}\left(\mathrm{S}_{\mathrm{i}}\right)$ is the random effect of cow nested in sequence $(\mathrm{k}=1$ to 9 ), $\mathrm{T}_{1}$ is the fixed effect of treatment ( $\mathrm{l}=1$ to 3$), \mathrm{H}_{\mathrm{m}}$ is the fixed effect of time of day ( $m$ depends on the variable), $\mathrm{T}_{1} \times \mathrm{H}_{\mathrm{m}}$ is the interaction of treatment and time of day, and $\mathrm{e}_{\mathrm{ijk} k \mathrm{~m}}$ is the residual error. The $\operatorname{ANTE}(1)$ and UN covariance structures were used for plasma variables and fecal NDF and iNDF concentration (unequal spacing) and the $\mathrm{AR}(1)$ and $\mathrm{ARH}(1)$ covariance structures were used for the rate of feed intake, body temperature, and lying behavior (equal spacing). Covariance structures were selected based on model fit, time was the repeated variable, cow by treatment was the subject, and denominator degrees of freedom were adjusted by the Kenward-Rogers method. Daily parameters (e.g., milk production and composition, intake, and apparent 
total-tract digestibility) were analyzed with a reduced model in JMP (version 9, SAS Institute Inc., Cary, NC). Data were log-transformed when appropriate and back-transformed data are reported. The preplanned contrasts tested were AM versus PM and AM versus AMPM at each time point. Feeding and lying behavior and body temperature were originally analyzed over both 30-min and 2-h intervals. Data averaged over 2-h intervals was sufficient to characterize treatment differences and was used for data interpretation and means over 30-min intervals are reported in the data supplement (Supplemental Figures S1 to S3; http://dx.doi. org/10.3168/jds.2014-8261).

The cosine function models a repeating rhythm that can vary in the amplitude, time between peaks (period), and time at peak (phase). Determination of these parameters provides a simple description of the rhythms of complex data. Feeding behavior, lying behavior, and body temperature averaged over 30-min intervals was fit to the linear form of a cosine function with a 24-h period using SAS and the following model:

$$
\begin{gathered}
\mathrm{Y}_{\mathrm{ijklm}}=\mathrm{M}+\mathrm{S}_{\mathrm{i}}+\mathrm{P}_{\mathrm{j}}+\mathrm{C}_{\mathrm{k}}+\mathrm{I}\left(\mathrm{C}_{\mathrm{k}}\right)+\mathrm{T}_{\mathrm{m}} \\
+A \cos \left(2 \pi \mathrm{t}_{\mathrm{l}} / 24\right)+B \sin \left(2 \pi \mathrm{t}_{\mathrm{l}} / 24\right)+\mathrm{T}_{\mathrm{m}} \\
\times A \cos \left(2 \pi \mathrm{t}_{\mathrm{l}} / 24\right)+\mathrm{T}_{\mathrm{m}} \times B \sin \left(2 \pi \mathrm{t}_{\mathrm{l}} / 24\right) \\
+C \cos \left(2 \pi \mathrm{t}_{\mathrm{l}} / 12\right)+D \sin \left(2 \pi \mathrm{t}_{\mathrm{l}} / 12\right)+\mathrm{T}_{\mathrm{m}} \\
\times C \cos \left(2 \pi \mathrm{t}_{\mathrm{l}} / 12\right)+\mathrm{T}_{\mathrm{m}} \times D \sin \left(2 \pi \mathrm{t}_{\mathrm{l}} / 12\right)+\mathrm{e}_{\mathrm{ijklm}},
\end{gathered}
$$

where $\mathrm{Y}_{\mathrm{ijklm}}$ is the variable of interest, $\mathrm{M}$ is mesor (daily mean), $\mathrm{S}_{\mathrm{i}}$ is the random effect of sequence ( $\mathrm{i}=1$ to 6$), P_{j}$ is the random effect of period ( $\mathrm{j}=1$ to 3$), \mathrm{C}_{\mathrm{k}}$ is the random effect of cow ( $\mathrm{k}=1$ to 9$), \mathrm{I}\left(\mathrm{C}_{\mathrm{k}}\right)$ is the random effect of intercept with cow as subject, $\mathrm{T}_{\mathrm{m}}$ is treatment ( $\mathrm{m}=1$ to 3$), \mathrm{t}_{1}$ is time, and $\mathrm{e}_{\mathrm{ijk} k \mathrm{~m}}$ is the residual error. Coefficients of the linear form of the cosine function within a 24-h period are indicated as $A$ and $B$, and coefficients of the 12-h harmonic are indicated as $C$ and $D$. Reduction of the model, including removal of the 12-h harmonic, was based on Bayesian information criterion. A zero amplitude $F$-Test comparing the cosine fit to a linear fit was used to determine the significance of the cosine fit for each treatment. Amplitude was calculated as $\sqrt{A^{2}+B^{2}}$ and phase was calculated as $[\arctan (\mathrm{B} / \mathrm{A}) \times 12 / \pi]$ and reported as acrophase, which is the time at which the peak of a rhythm occurs (Bourdon et al., 1995). The 95\% confidence limits were determined for amplitude and phase according to Bourdon et al. (1995). Significant differences were defined as a difference of amplitude or phase greater than 1.96 times the square root of sum of squares of the standard errors $(P<0.05$; Knezevic, 2008). In all analyses, data points with Studentized residuals outside of \pm 3 were considered outliers and were removed from analysis. Rarely more than 1 data point per variable was removed.

\section{RESULTS}

\section{Milk Production and FA Profile}

Treatment had no effect on daily milk yield and concentration and yield of milk fat and protein (Table 2). Also, no treatment by milking time interactions were observed, although some tendencies for differences between treatments were detected by the preplanned contrasts for milk and milk fat yield at individual milking times (Supplemental Table S1; http://dx.doi. org/10.3168/jds.2014-8261). Interestingly, PM and AMPM feeding tended to increase milk yield $0.9(P$ $=0.09)$ and $1.0 \mathrm{~kg}(P=0.06)$, respectively, at the 1700-h milking compared with AM feeding. Additionally, AMPM feeding tended to decrease fat yield at the 0500-h milking by $70 \mathrm{~g}$ compared with AM feeding ( $P$ $=0.08)$. Milk and milk protein yields were higher for all treatments at the 0500-h milking compared with the 1700-h milking ( $1.4 \mathrm{~kg}, P<0.01 ; 0.4 \mathrm{~kg}, P=0.01$, respectively). Importantly, milking $2 \times / \mathrm{d}$ provides limited ability to observe changes in the daily rhythm of milk synthesis and is dependent on the timing of milking relative to the rhythms.

Treatments had little effect on the daily weighted average milk FA profile, including no change in intermediates of ruminal FA biohydrogenation or the proportion of de novo and preformed FA (Table 2). However, milk FA profile varied between morning and afternoon milking, and a numerically small, but significant, treatment by milking interaction was observed for some FA (Supplemental Table S2; http://dx.doi.org/10.3168/ jds.2014-8261). Briefly, trans-11 C18:1 was not different between treatments at the 0500-h milking, but tended to be decreased $5.6 \%$ by AMPM compared with AM feeding at the 1700-h milking. The concentration of de novo synthesized FA was $2 \%$ higher for AM than PM feeding at the 0500-h milking, but not different at the 1700-h milking.

\section{Feed Intake, Apparent Total-Tract Digestibility, and Feeding and Lying Behavior}

No effect of treatment on daily DMI was observed. The amount of $\mathrm{OM}$ digested tended to be decreased by PM and AMPM compared with AM feeding and amount of NDF digested was decreased by AMPM feeding compared with AM feeding (Table 3). Digestibility of OM and NDF were not different between AM 
Table 2. Effect of feeding time on daily milk and milk component yield, milk composition, and feed intake and efficiency

\begin{tabular}{|c|c|c|c|c|c|c|c|}
\hline \multirow[b]{2}{*}{ Item } & \multicolumn{3}{|c|}{ Treatment $\mathrm{LSM}^{1}$} & \multirow[b]{2}{*}{$\mathrm{SE}$} & \multicolumn{3}{|c|}{$P$-value ${ }^{2}$} \\
\hline & $\mathrm{AM}$ & $\mathrm{PM}$ & AMPM & & Trt & AM vs. PM & $\begin{array}{l}\text { AM vs. } \\
\text { AMPM }\end{array}$ \\
\hline DMI (kg/d) & 32.6 & 31.4 & 31.9 & 0.92 & 0.40 & 0.18 & 0.44 \\
\hline \multicolumn{8}{|l|}{ Yield $(\mathrm{kg} / \mathrm{d})$} \\
\hline Milk & 50.0 & 50.5 & 50.8 & 2.62 & 0.69 & 0.59 & 0.40 \\
\hline Milk fat & 1.72 & 1.72 & 1.75 & 0.04 & 0.84 & 0.99 & 0.62 \\
\hline Milk protein & 1.48 & 1.49 & 1.50 & 0.06 & 0.77 & 0.78 & 0.48 \\
\hline \multicolumn{8}{|l|}{ Milk composition (\%) } \\
\hline Fat & 3.51 & 3.49 & 3.48 & 0.15 & 0.90 & 0.83 & 0.66 \\
\hline Protein & 2.97 & 2.95 & 2.96 & 0.07 & 0.80 & 0.52 & 0.69 \\
\hline \multicolumn{8}{|l|}{ Milk FA ( $\%$ of FA) } \\
\hline trans-10 C18:1 & 0.45 & 0.46 & 0.45 & 0.02 & 0.59 & 0.31 & 0.59 \\
\hline trans-11 C18:1 & 1.05 & 1.06 & 1.02 & 0.06 & 0.53 & 0.81 & 0.41 \\
\hline cis-9,trans-11 CLA & 0.48 & 0.48 & 0.49 & 0.03 & 0.83 & 0.96 & 0.62 \\
\hline trans-10,cis-12 CLA & $\mathrm{ND}^{3}$ & ND & ND & - & - & - & - \\
\hline$\Sigma \mathrm{FA}<16 \mathrm{C}^{4}$ & 27.4 & 27.2 & 27.4 & 0.6 & 0.73 & 0.47 & 0.89 \\
\hline$\Sigma \mathrm{FA}>16 \mathrm{C}$ & 37.9 & 38.1 & 37.6 & 0.8 & 0.28 & 0.50 & 0.34 \\
\hline$\Sigma 16 \mathrm{C}$ & 27.4 & 27.5 & 27.6 & 0.8 & 0.69 & 0.59 & 0.41 \\
\hline
\end{tabular}

${ }^{1} \mathrm{AM}=$ feeding once a day at $0830 \mathrm{~h} ; \mathrm{PM}=$ feeding once a day at $2030 \mathrm{~h} ; \mathrm{AMPM}=$ feeding twice a day in equal amounts at 0830 and $2030 \mathrm{~h}$.

${ }^{2}$ Trt $=$ is the overall effect of treatment; preplanned contrasts tested were AM vs. PM and AM vs. AMPM.

${ }^{3} \mathrm{ND}=$ below the level of detection.

${ }^{4}$ Fatty acids $<16$ carbon $(\mathrm{C})$ originate from the mammary gland (C15:0 is not included); FA $>16 \mathrm{C}$ originate from plasma; 16-C FA originate from both sources.

and PM feeding, but were decreased by AMPM feeding compared with AM feeding. No overall effect of treatment on daily intake of OM and NDF (data not shown) or the average number of meals per day, meal length, intermeal interval, meal frequency, meal size, and eating rate was noted (Table 3 ).

A treatment by time of day interaction was seen for the timing of feed intake over the day $(P<0.01$; Figure
1). Over 20 and $34 \%$ of daily DMI was consumed in the first $2 \mathrm{~h}$ after feeding for the AM and PM feeding, respectively, and 15.6 and $27.4 \%$ of daily intake for AMPM feeding in the morning and evening, respectively. Feed intake of AM-fed was higher than PM-fed cows during the first $2 \mathrm{~h}$ after the 0830-h feeding $(P<$ 0.01 ), whereas $\mathrm{PM}$ was higher than AM during the first $2 \mathrm{~h}$ after the 2030-h feeding $(P<0.01)$. A tendency for

Table 3. Effect of feeding time on daily nutrient intake, apparent total-tract digestibility, and meal parameters in lactating cows

\begin{tabular}{|c|c|c|c|c|c|c|c|}
\hline \multirow[b]{2}{*}{ Item } & \multicolumn{3}{|c|}{ Treatment $\mathrm{LSM}^{1}$} & \multirow[b]{2}{*}{$\mathrm{SE}$} & \multicolumn{3}{|c|}{$P$-value ${ }^{2}$} \\
\hline & $\mathrm{AM}$ & PM & AMPM & & Trt & AM vs. PM & $\begin{array}{l}\text { AM vs. } \\
\text { AMPM }\end{array}$ \\
\hline \multicolumn{8}{|l|}{$\overline{\mathrm{OM}}$} \\
\hline Digested (kg/d) & 21.2 & 20.2 & 20.1 & 0.4 & 0.11 & 0.09 & 0.06 \\
\hline Digestibility (\%) & 73.1 & 72.4 & 72.2 & 0.30 & 0.18 & 0.16 & 0.08 \\
\hline \multicolumn{8}{|l|}{$\mathrm{NDF}$} \\
\hline Digested (kg/d) & 4.6 & 4.4 & 4.3 & 0.1 & 0.03 & 0.06 & 0.01 \\
\hline Digestibility (\%) & 48.8 & 47.7 & 47.2 & 0.59 & 0.19 & 0.24 & 0.08 \\
\hline \multicolumn{8}{|l|}{ Meals } \\
\hline Bouts/d & 11.2 & 11.2 & 11.5 & 0.8 & 0.76 & 0.94 & 0.56 \\
\hline Length (min/meal) & 38.5 & 37.6 & 36.6 & 2.5 & 0.40 & 0.54 & 0.19 \\
\hline Interval (min) & 88.7 & 89.8 & 91.4 & 6.5 & 0.86 & 0.83 & 0.59 \\
\hline Size (kg of DM/meal) & 3.0 & 3.0 & 3.0 & 0.2 & 0.96 & 0.80 & 0.79 \\
\hline Eating rate $\left(\mathrm{kg} / \mathrm{min}^{3}\right)$ & 0.079 & 0.078 & 0.086 & 0.004 & 0.26 & 0.82 & 0.20 \\
\hline
\end{tabular}

${ }^{1} \mathrm{AM}=$ feeding once a day at $0830 \mathrm{~h} ; \mathrm{PM}=$ feeding once a day at $2030 \mathrm{~h} ; \mathrm{AMPM}=$ feeding twice a day in equal amounts at 0830 and $2030 \mathrm{~h}$.

${ }^{2}$ Trt $=$ is the overall effect of treatment; preplanned contrasts tested were AM vs. PM and AM vs. AMPM.

${ }^{3}$ Eating rate calculated as meal size (DM basis) divided by meal length. 
greater intake was also observed in the first $2 \mathrm{~h}$ after the 0830-h feeding for AM compared with AMPM feeding $(P=0.06)$, as well as greater intake in the first $2 \mathrm{~h}$ after the 2030-h feeding for PM compared with AMPM $(P<0.01)$. Spontaneous feeding for AM-fed was higher than PM-fed cows for $6 \mathrm{~h}$ during the afternoon (1230 to $1830 \mathrm{~h} ; P<0.05)$ and AM feeding was also higher than AMPM feeding during one 2-h interval in the early evening (1730 h; $P=0.03)$. However, spontaneous feeding followed a similar pattern among all treatments, including a low level of intake overnight (2400 to $0500 \mathrm{~h} ; 2.2$ $\pm 0.74 \% / \mathrm{h})$ and a moderate level of intake in the afternoon (1200 to 1700 h; $4.8 \pm 1.1 \%$ h; Figure 1$)$. Intake during spontaneous feeding periods fit a cosine function within a 24 -h period in all treatments $(P<0.01$; Table 4 ), was phase-advanced nearly $3 \mathrm{~h}$ by AMPM, and was phase-delayed 22 min by PM compared with AM. Compared with AM, the amplitude of the rate of spontaneous feed intake was decreased 1.3 and 0.9 percentage units for PM and AMPM, respectively $(P<0.05)$.

No main effect of treatment was seen, but a treatment by time of day interaction was noted for lying behavior $(P<0.01$; Figure 1$)$. The proportion of time spent lying down was reduced by 12 percentage units by AM compared with PM feeding from 1700 through $1900 \mathrm{~h}(P<0.05)$, but was increased 17 percentage units by AM compared with PM feeding at $2100 \mathrm{~h}(P<$ 0.01 ; Figure 1). Rhythmicity was detected in all treatments by the cosine function $(P<0.01$; Table 4$)$. The acrophases of PM (0952 h) and AMPM (0814 h) feeding were delayed from AM feeding $(0724 \mathrm{~h} ; P<0.05)$, and the amplitude was decreased 2.3 and 2.9 percentage units by PM and AMPM compared with AM feeding, respectively $(P<0.05)$.

\section{Fecal Concentration of NDF and iNDF}

A treatment by time of day interaction was observed for fecal NDF and iNDF concentration as a percent of DM $(P<0.01$; Figure 2). Fecal NDF concentration gradually rose from 1030 through $1830 \mathrm{~h}$ for AM and from 1530 through $2230 \mathrm{~h}$ for both PM and AMPM. Fecal NDF concentration of AM feeding was $6.3 \%$ (or 3.4 units) higher compared with PM from 1530 through $1830 \mathrm{~h}$, but $6.8 \%$ (or 3.7 units) lower at $0330 \mathrm{~h}$ ( $P$ $<0.05$ ), whereas AM was $4.2 \%$ (or 2.4 units) higher relative to AMPM feeding at $1830 \mathrm{~h}$, but $3.6 \%$ (or 1.9 units) lower at $1030 \mathrm{~h}$. The concentration of fecal iNDF followed a similar pattern. Briefly, fecal iNDF increased over the same periods as fecal NDF for AM and AMPM feeding, but fecal iNDF concentration progressively increased after $1030 \mathrm{~h}$ and reached a peak at $2230 \mathrm{~h}$ for PM feeding. Fecal iNDF concentration at AM feeding was $7.1 \%$ (or 2.4 units) higher than PM feeding and

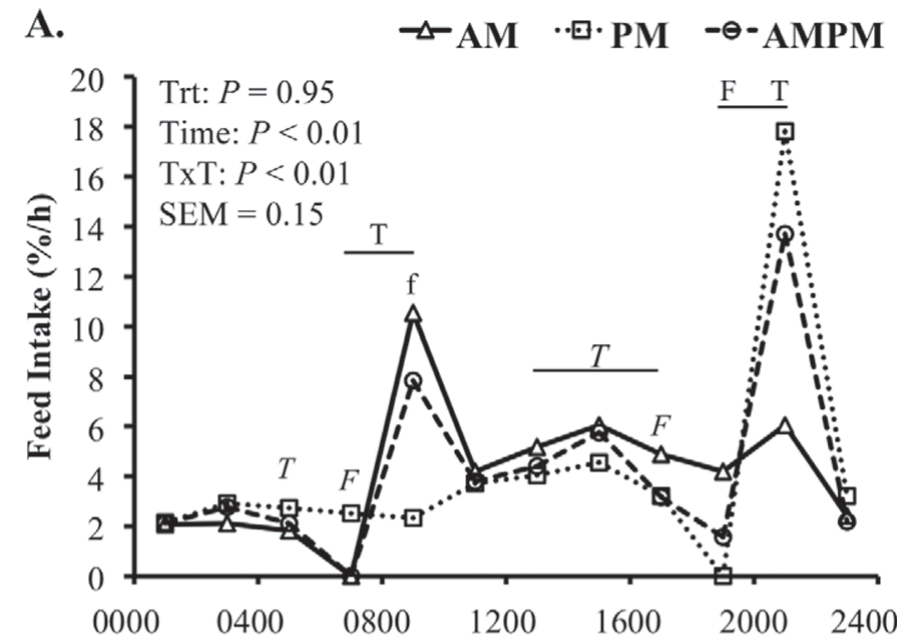

B.

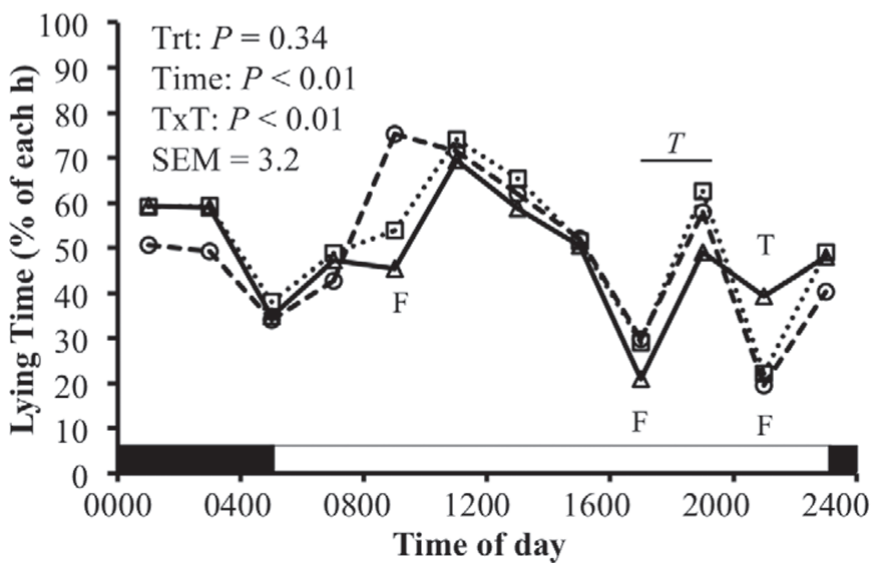

Figure 1. Effect of feeding time on the daily rhythm of feed intake and lying activity. Cows were fed the same TMR once a day at 0830 $\mathrm{h}(\mathrm{AM})$, once a day at $2030 \mathrm{~h}(\mathrm{PM})$, or twice a day in equal amounts at 0830 and $2030 \mathrm{~h}$ (AMPM). Data were averaged over 2-h intervals. Main effects of treatment (trt) and time and their interaction (TxT) are shown within each panel. Preplanned contrasts tested were AM vs. $\mathrm{PM}\left({ }^{\mathrm{T}}=P<0.01,{ }^{T}=P<0.05\right)$ and AM and AMPM $\left({ }^{\mathrm{F}}=P<0.01\right.$, $F=P<0.05)$ at each 2 -h interval. Light and dark phases are shown along the $\mathrm{x}$-axis of $\mathrm{B}$.

tended to be higher than AMPM feeding at $1530 \mathrm{~h}$, but was lower than PM and tended to be lower than AMPM at $0330 \mathrm{~h}(P<0.05)$. Lastly, an effect of time was seen, but no treatment by time of day interaction for iNDF as a percent of NDF $(P=0.64)$.

The daily pattern of fecal NDF and iNDF concentration fit a cosine function within a $24-\mathrm{h}$ period in all treatments $(P<0.01 ;$ Table 4$)$. The acrophase of fecal NDF concentration for PM (0100 h) and AMPM (2335 h) feeding were both different from AM feeding (1952 h; $P<0.05)$. The amplitude of fecal NDF was increased 0.3 percentage units by PM feeding and decreased 0.8 percentage units for AMPM compared with AM feeding $(P<0.05)$. The acrophase and amplitude of fecal iNDF was similarly modified by PM and AMPM com- 
NIU ET AL.

Table 4. Effect of feeding time on the fit of a cosine function with a 24-h period on key variables in lactating cows



pared with AM feeding. In addition, the cosine function within a 24-h period tended to fit iNDF as a percent of NDF for AM feeding $(P=0.07)$.

\section{Plasma Metabolites and Hormones}

A treatment by time of day interaction was noted for plasma glucose concentration $(P=0.02$; Figure $3 \mathrm{~A}$ ). The concentration of plasma glucose was $7.9 \%$ (or $4.3 \mathrm{mg} / \mathrm{dL}$ ) lower in AM relative to AMPM feeding 2 $\mathrm{h}$ after the 0830 -h feeding $(P<0.05)$ and $16.5 \%$ (or $8.0 \mathrm{mg} / \mathrm{dL}$ ) higher $2 \mathrm{~h}$ after the 2030 -h feeding in AM compared with PM and AMPM feeding $(P<0.01$ and $P<0.05$, respectively). Daily rhythmicity was detected for plasma glucose concentration by cosine fit for all treatments $(P<0.01$; Table 4$)$. The acrophase for AM $(0216 \mathrm{~h})$ was delayed more than $6 \mathrm{~h}$ by PM and AMPM feeding $(P<0.05)$, and the amplitude was increased 1.3 $\mathrm{mg} / \mathrm{dL}$ by PM compared with AM feeding $(P<0.05)$.

A treatment by time of day interaction was observed for plasma insulin concentration $(P<0.01$; Figure 3$)$. Relative to AM feeding, plasma insulin was decreased, on average, $60 \%$ (or $3.3 \mu \mathrm{IU} / \mathrm{mL}$ ) by PM feeding from 1030 to $1830 \mathrm{~h}(P<0.05)$, but increased $164 \%$ on 


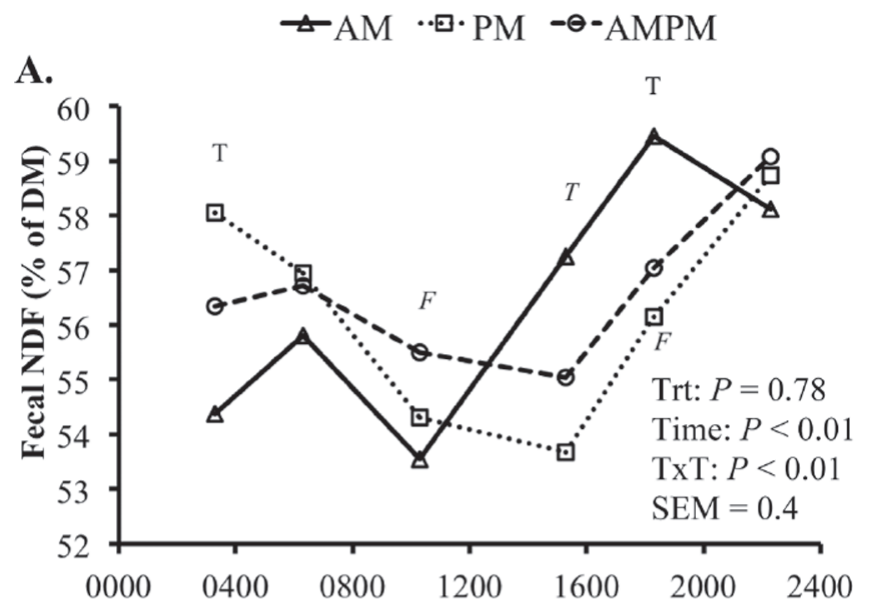

B.

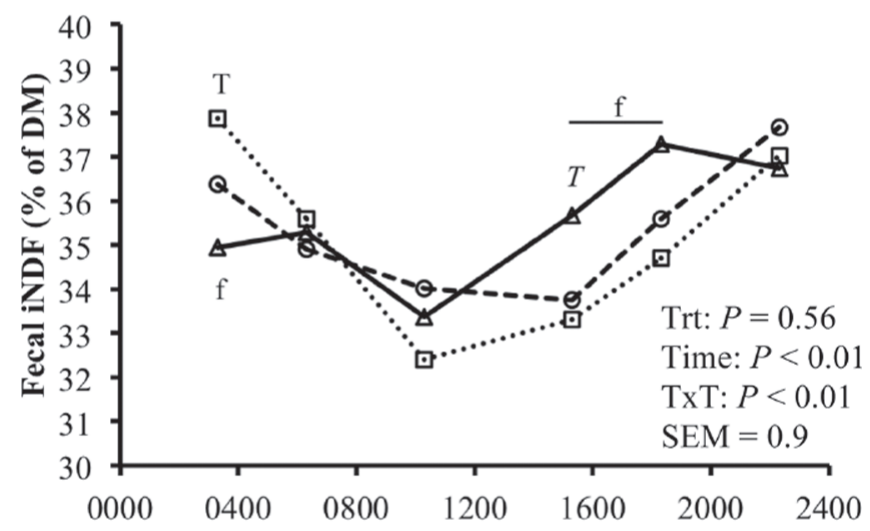

C.

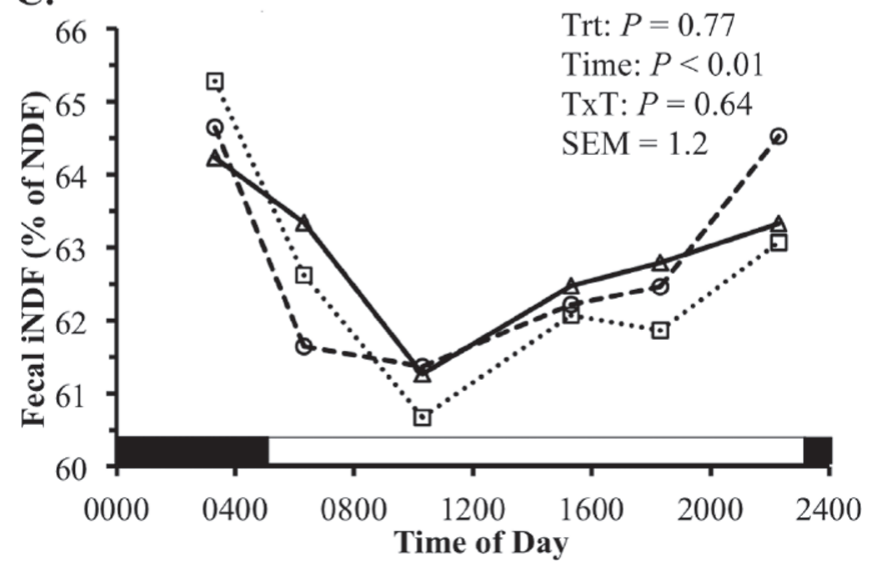

Figure 2. Effect of feeding time on the daily rhythm of fecal NDF and indigestible NDF. Cows fed once a day at $0830 \mathrm{~h}$ (AM), once a day at $2030 \mathrm{~h}(\mathrm{PM})$, or twice a day in equal amounts at 0830 and $2030 \mathrm{~h}$ (AMPM). Main effects of treatment (trt) and time and their interaction (TxT) are shown within each panel. Preplanned contrasts tested were AM vs. $\mathrm{PM}\left({ }^{\mathrm{T}}=P<0.01,{ }^{T}=P<0.05\right)$ and $\mathrm{AM}$ vs. $\mathrm{PM}\left({ }^{F}=\right.$ $\left.P<0.05,{ }^{\mathrm{f}}=P<0.1\right)$ at each time point. Light and dark phases are shown along the $\mathrm{x}$-axis of $\mathrm{C}$. average (or $9.2 \mu \mathrm{IU} / \mathrm{mL}$ ) from 2230 through $0330 \mathrm{~h}$ $(P<0.01)$. The concentration of plasma insulin was increased $96 \%$ (or $7.1 \mu \mathrm{IU} / \mathrm{mL}$ ) by AMPM compared with AM feeding only at $2230 \mathrm{~h}(P<0.05)$. Additionally, plasma insulin concentration of PM and AMPM fit a cosine function within a 24 -h period $(P<0.01$; Table 4). Acrophase was delayed by PM (0031 h) and AMPM $(2220 \mathrm{~h})$ feeding compared with AM (1844 h; $P<0.05)$. The amplitude was also increased by PM and AMPM compared with AM feeding by 6.5 and 3.0 $\mu \mathrm{IU} / \mathrm{mL}$, respectively $(P<0.05)$.

A tendency for an interaction of treatment and time of day was seen for plasma NEFA concentration $(P=$ 0.11 ; Figure $3 \mathrm{~B})$. The concentration of plasma NEFA was $27 \mu \mathrm{Eq} / \mathrm{L}$ higher for AM than PM feeding at 0630 $\mathrm{h}$, but $23 \mu \mathrm{Eq} / \mathrm{L}$ lower at $1030 \mathrm{~h}(P<0.05)$. Both AM and AMPM feeding had a higher concentration of NEFA $2 \mathrm{~h}$ before the 0830-h feed delivery, however, PM was more consistent over the day. The acrophase was delayed $4 \mathrm{~h}$ by AMPM $(0740 \mathrm{~h})$ compared with AM (0342 h), and amplitude was also decreased 12.9 $\mu \mathrm{Eq} / \mathrm{L}$ by AMPM compared with AM $(P<0.05$; Table 4). However, plasma NEFA concentration failed to fit a cosine function within a 24-h period with PM feeding.

We observed a treatment by time of day interaction for BUN $(P<0.01$; Figure 3$)$. The concentration of BUN was $1.4 \mathrm{mg} / \mathrm{dL}$ higher for PM compared with AM feeding from 1830 through $0330 \mathrm{~h}$, but $1.7 \mathrm{mg} / \mathrm{dL}$ lower at $1030 \mathrm{~h}(P<0.05)$. Blood urea nitrogen was $1.7 \mathrm{mg} /$ $\mathrm{dL}$ higher at $2230 \mathrm{~h}$ and tended to be higher at $0630 \mathrm{~h}$ for AMPM compared with AM feeding $(P<0.01$ and $P=0.07$, respectively). A rise in BUN was observed shortly after feeding with AM and PM feeding, peaking around 1030 and $2230 \mathrm{~h}$, respectively, and AMPM rose during both of these periods. All treatments fit a cosine function within a 24 -h period $(P<0.01$; Table 4$)$. The acrophase of BUN for AM feeding (1342 h) was delayed $8 \mathrm{~h}$ by $\mathrm{PM}$ feeding $(P<0.05)$, and the amplitude increased $0.1 \mathrm{mg} / \mathrm{dL}$ in PM compared with AM feeding $(P<0.05)$. Relative to AM, AMPM did not change the acrophase, but decreased the amplitude by $0.6 \mathrm{mg} / \mathrm{dL}$ $(P<0.05)$.

\section{Core Body Temperature}

Core body temperature is predominantly regulated by a light-entrainable oscillator located in SCN of the hypothalamus (Liu et al., 2002) and was observed to provide insight into the modification of the central master clock. A treatment by time of day interaction was noted for body temperature $(P<0.01$; Figure 4$)$. Body temperature was higher for AM than PM and AMPM feeding from 2300 to $0100 \mathrm{~h}(P<0.05)$. Two peaks were observed around 0800 and $2000 \mathrm{~h}$ for all 
A.

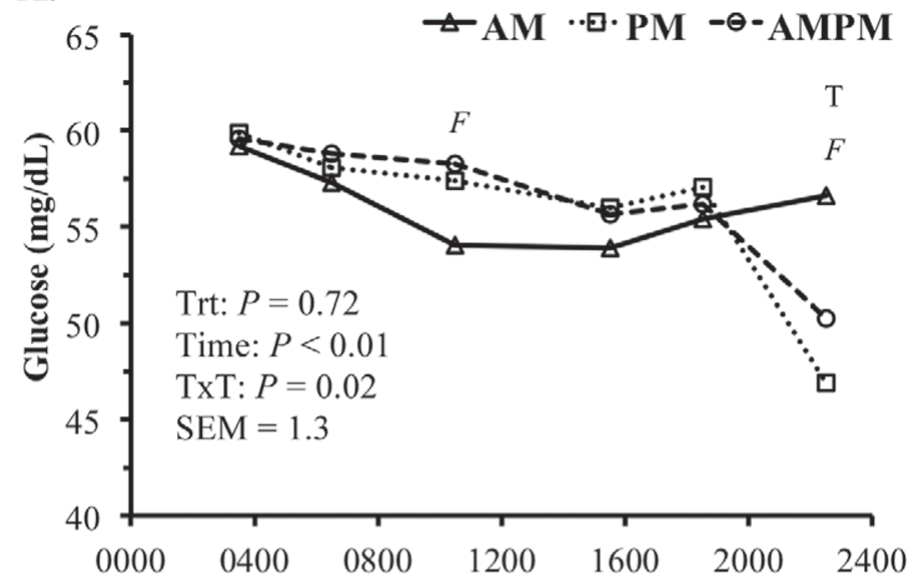

B.

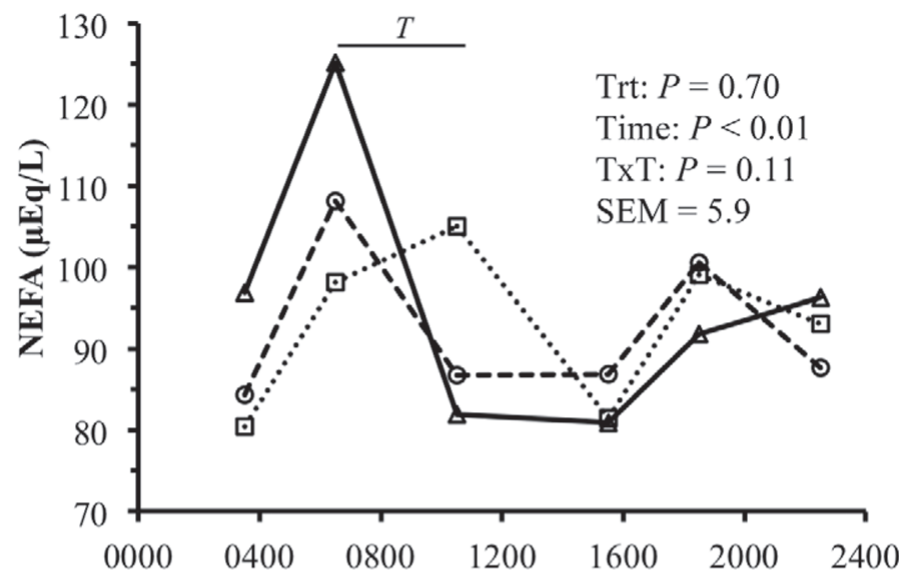

C.

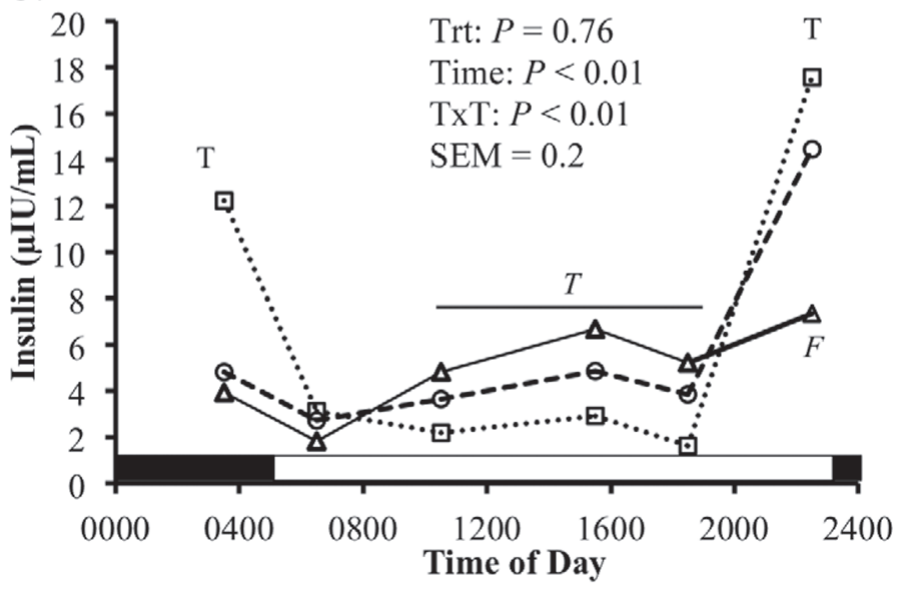

D.

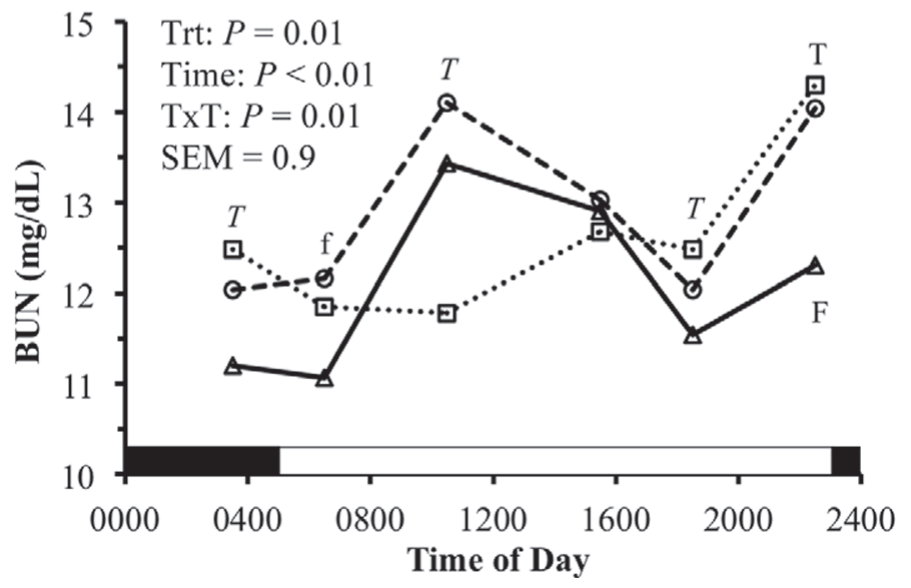

Figure 3. Effect of feeding time on the daily rhythm of plasma glucose, insulin, NEFA, and blood urea nitrogen (BUN) concentration. Cows were fed the same diet once a day at $0830 \mathrm{~h}(\mathrm{AM})$, once a day at $2030 \mathrm{~h}(\mathrm{PM})$, or twice a day in equal amounts at 0830 and $2030 \mathrm{~h}(\mathrm{AMPM})$. Main effects of treatment (trt) and time and their interaction (TxT) are shown within each panel. Preplanned contrasts tested were AM vs. $\mathrm{PM}\left({ }^{\mathrm{T}}=P<0.01,{ }^{\mathrm{T}}=P<0.05\right)$ and AM vs. $\mathrm{PM}\left({ }^{\mathrm{F}}=P<0.01,{ }^{F}=P<0.05\right.$, and $\left.{ }^{\mathrm{f}}=P<0.1\right)$ at each time point. Light and dark phases are shown along the $\mathrm{x}$-axis of $\mathrm{C}$ and $\mathrm{D}$.

treatments, but body temperature for $\mathrm{AM}$ feeding maintained a higher temperature past $0100 \mathrm{~h}$. Rhythmicity was detected for both AM and PM feeding $(P<$ 0.01; Table 4), but not AMPM feeding. The acrophase of AM feeding $(2351 \mathrm{~h}$ ) was delayed approximately $3 \mathrm{~h}$ by PM feeding and the amplitude of body temperature was decreased $0.11^{\circ} \mathrm{C}$ by PM compared with AM feeding $(P<0.05)$.

\section{DISCUSSION}

The main objective of the experiment was to determine the effect of feeding time on the daily pattern of feeding behavior and other daily rhythms important to metabolism and management of dairy cows. Offering fresh feed to dairy cows at different times of day and at different frequencies required behavior and physi- ological adaptations. For example, approximately $63 \%$ of feed was consumed during the first $12 \mathrm{~h}$ after feeding in the AM-fed cows, but AMPM cows were only fed $50 \%$ of daily intake at each feeding. Cows quickly adjusted to the feeding schedules, although the changes in feeding behavior between treatments predominantly occurred during the conditioned feeding periods after feeding. This shift in feeding behavior had physiologically important effects on metabolism including plasma glucose, insulin, and NEFA concentration.

Total daily DMI was not affected by feeding once per day in the morning compared with the evening, in agreement with Nikkhah et al. (2008). Additionally, DeVries and von Keyserlingk (2005) reported no difference in daily DMI when fresh feed was offered immediately after milking compared with $6 \mathrm{~h}$ after milking, and no difference in daily DMI was detected in feedlot cattle 


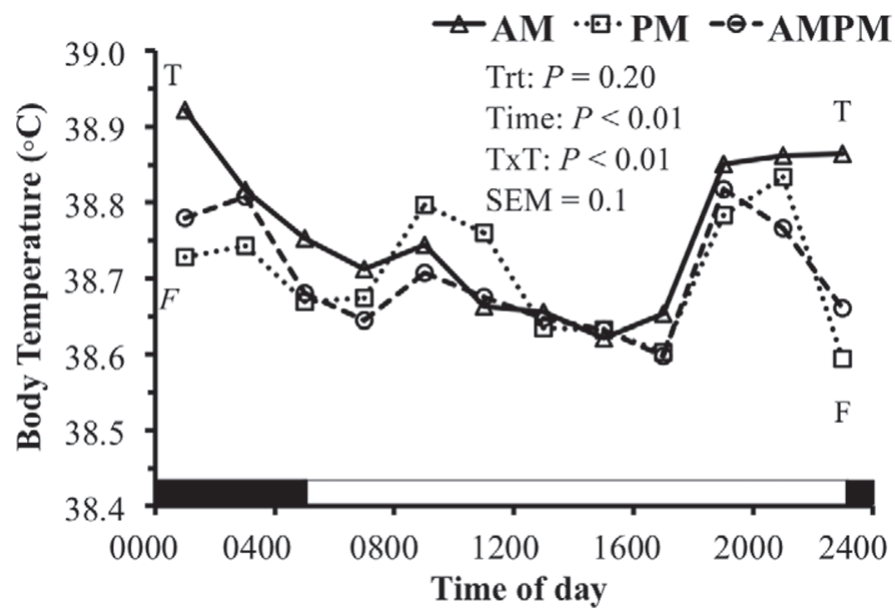

Figure 4. Effect of feeding time on the daily rhythm of body temperature. Cows were fed the same diet once a day at $0830 \mathrm{~h}$ (AM), once a day at $2030 \mathrm{~h}(\mathrm{PM})$, or twice a day in equal amounts at 0830 and $2030 \mathrm{~h}$ (AMPM). Data were averaged over 2-h intervals. Main effects of treatment (trt) and time and their interaction (TxT) are shown within each panel. Preplanned contrasts tested were AM vs. $\mathrm{PM}\left({ }^{\mathrm{T}}=P<0.01\right)$ and AM vs. $\mathrm{PM}\left({ }^{\mathrm{F}}=P<0.01,{ }^{F}=P<0.05\right)$ at each time point. Light and dark phases are shown along the $\mathrm{x}$-axis.

fed in the morning compared with the evening (Kennedy et al., 2004). However, changing feeding time was reported to modify feeding behavior by changing the amount of feed consumed at specific times of the day in several studies. The largest effect on feeding behavior in the current study was on conditioned feeding following feed delivery. Delivery of fresh feed has repeatedly been demonstrated to be a strong stimulus for eating in dairy cows. For example, DeVries et al. (2005) showed spikes in the number of cows at the feed bunk following each feeding when cows were fed 1 to 4 times per day. Spontaneous feed intake over the rest of the day in the current experiment can generally be divided into a moderate rate of intake period during the afternoon and a low rate of intake period during the overnight. Similarly, cow attendance at the feed bunk was consistently higher during the light phase compared with the overnight and early morning period in experiments that changed the schedule and frequency of feeding, demonstrating the robustness of the daily rhythm of spontaneous feeding (DeVries et al., 2003; DeVries and von Keyserlingk, 2005; DeVries et al., 2005).

Standing and lying behavior is considered an important indicator of cow comfort and health and changing feed delivery time shifted the daily pattern of lying similar to DeVries et al. (2012). These changes appear to be driven by changes in feeding behavior, but are important to consider when conducting audits of lying behavior. Lastly, daily rhythms in core body temperature were detected for all treatments in the current experiment and the observed phase and amplitude changes may indicate entrainment of the central biological clock by feeding time.

Interestingly, in the current study, feeding in the evening markedly increased the amount of feed consumed in the first $2 \mathrm{~h}$ after evening feeding compared with morning feeding. This may be a compensation for the small reduction in spontaneous feeding observed in the early afternoon. Similarly, Nikkhah et al. (2008) reported that intake within the first $3 \mathrm{~h}$ after feeding was over $40 \%$ higher for cows fed at $2100 \mathrm{~h}$ compared with feeding at $0900 \mathrm{~h}$. Importantly, even though a large difference in intake after feed delivery was observed, very few differences in intake during the low-intake period were noted during the overnight and the moderate intake period during the afternoon. This data supports a natural circadian rhythm of spontaneous feed intake in the dairy cow that is not entrained by feeding time. Based on literature in other experimental models, it is expected that the timing and length of the light and dark periods are predominant entrainers of this daily rhythm, although a role of milking schedule cannot be ruled out. This observation has important implications for feeding at night that is sometime recommended during heat stress periods. However, this approach is expected to fail to increase overnight intake. The large conditioned feeding periods in the evening are expected to increase the risk of acidosis as a large amount of fermentable substrate enters the rumen, which is supported by the change in plasma glucose and insulin observed. However, feeding at night may be a strategy to increase plasma insulin during periods when increased adipose lipogenesis or decreased adipose lipolysis is desired.

Cosine analysis is a robust, efficient, and widely accepted approach to characterizing circadian rhythms (Bourdon et al., 1995), as it provides a simple and testable characterization of complex rhythms. Generally, cosine functions are either fit to individual animals and then ANOVA analysis is conducted on the resulting parameters (amplitude and phase) or fit to the treatment means, which does not allow statistical testing between treatments. We have integrated the cosine function into a mixed model allowing modeling of cow and period variation important to replicated designs. The high-resolution feed observation data in the current experiment was well suited to cosine analysis, although the method has not been routinely used in analysis of feeding behavior of dairy cows. Data from immediately before and after feeding (no feed available and conditioned meals, respectively) and milking times were removed to allow analysis of spontaneous feeding behavior. The observed changes in the rhythm included changes in both amplitude and phase in the current study. As a result of the lower rate of intake in the 
afternoon, evening feeding decreased the amplitude of spontaneous feeding compared with morning feeding.

Despite changes in the daily rhythm of feed intake, no effect on daily milk production or composition was seen. Additionally, milk yield was slightly higher at the morning than afternoon milking, but the difference observed in twice-a-day milking is expected to be highly dependent on the timing of milking.

Feeding multiple times per day has been reported to increase milk fat yield, presumably through stabilization of rumen fermentation (e.g., Rottman et al., 2014). Milk fat trans-11 C18:1 and cis-9,trans-11 CLA are indicators of the normal pathway of ruminal biohydrogenation of PUFA, whereas trans-10 C18:1 and trans-10,cis-12 CLA are produced under altered fermentation and are associated with milk fat depression (reviewed by Harvatine et al., 2009). Rottman et al. (2014) reported decreased intermediates of the altered ruminal biohydrogenation pathway and increased milk fat yield when cows were fed in 4 equal meals over the day compared with cows fed once per day, but the diet fed in that experiment resulted in lower milk fat $(3.1 \%$ milk fat). Nikkhah et al. (2008) reported increased milk fat concentration and yield with evening compared with morning feeding in multiparious cows when a diet that resulted in low milk fat $(\sim 2.5 \%$ milk fat $)$ was fed, demonstrating the ability of feeding time to stabilize rumen biohydrogenation. Furthermore, Nikkhah et al. (2008, 2011) has proposed that feeding time may be used as a management strategy to maintain stable rumen fermentation.

Rumen-cannulated cows were not used in the current experiment, but the daily patterns of fecal NDF provide insight into changes in the rhythm of rumen function. The mechanism of fiber digestion in the rumen has been extensively studied and modeled (e.g., Allen and Mertens, 1988), although their work has predominantly assumed steady state conditions. The pattern of feed intake directly affects the timing of nutrient entry into the rumen and is expected to change the amount and composition of rumen digesta. Additionally, feed intake and rumination cannot occur at the same time; thus, changes in the pattern of intake are expected to shift the timing of rumination and rumen motility. Changes in fecal NDF and iNDF concentration across the day in the current experiment may be explained by the large shift in the timing and amount of feed consumed at the conditioned meals or the acrophase shift and amplitude change of spontaneous feeding. Research on the mechanisms affecting fecal NDF and iNDF are limited. Fecal NDF and iNDF concentration were linearly decreased with increasing TMR particle size, and fecal $\mathrm{NDF}$, iNDF, and starch concentration appeared to follow a rhythm over the day with fecal NDF and iNDF rising after feeding and peaking 12 to $13 \mathrm{~h}$ later in cows fed $1 \times / d$ in the morning (Maulfair et al., 2011). Fecal NDF or iNDF concentration is expected to represent changes in the composition or rate of rumen outflow. Feed particles must be small and dense enough to pass through the ruminal-omasal orifice (Allen, 1996), but passage may also be affected by rumen fill and motility, factors that are influenced by the feeding pattern. Robinson et al. (2002) reported a change in the amino acid profile of duodenal flow across the day indicative of changes in RUP and microbial protein contribution, suggesting the composition of rumen outflow varies across the day. Interestingly, fecal iNDF as a percent of NDF varied across the day, but was not different between treatments, further supporting the hypothesis that composition of rumen outflow changes across the day. Future work using duodenally cannulated cows, or possibly ultrasonic flow meters, will be required to determine the change in rumen digesta composition and flow rates across the day.

Plasma BUN levels are known to follow a daily pattern that is modified by feeding schedules (Lefcourt et al., 1999; Piccione et al., 2007). In the current experiment, increases in BUN were associated with the timing of conditioned feeding after feed delivery and provides additional evidence that the timing of feeding modified rumen function across the day similar to that of fecal NDF and iNDF rhythms.

Plasma glucose, NEFA, and insulin concentration are interrelated and are responsive to the timing of nutrient absorption. The concentration of plasma insulin increased and plasma glucose decreased after evening feeding, but not after morning feeding. More feed was consumed after evening feeding, and an increase in nutrient absorption or change in gut hormones, such as glucose-dependent insulinotropic polypeptide and glucagon-like peptide-1 (Drucker, 2007), which were not measured, may explain the difference in insulin secretion. However, other factors, such as circadian variation, may be important. Specifically, the conditioned meal occurring after the moderate intake period in the afternoon may result in more propionate production in the rumen. Nikkhah et al. (2008) did not observe a difference in rumen propionate concentration relative to feeding in cows fed in the evening compared with the morning, but did observe a significant increase in plasma lactate after evening feeding (Nikkhah et al., 2011). Additionally, responsiveness of insulin secretion may also differ due to circadian changes in sensitivity or neural mechanisms (Ahrén, 2000; Drucker, 2007). Importantly, altering feeding time causes shifts in insulin regulation in other species. Briefly, isolated pancreatic islets have a circadian rhythm of insulin secretion controlled by an endogenous clock (Reviewed by Bass, 
2012). In human and rodents, both the time of the day and sleep modify the response to a glucose tolerance test (e.g., Van Cauter et al., 1991), and rhythms of glucose concentration and insulin secretion are maintained during fasting in humans, indicating a regulatory mechanism independent of food intake (Troisi et al., 2000; Merl et al., 2004).

The concentration of plasma NEFA is commonly reported to increase during the overnight period, peak before morning feed delivery, and decline when insulin rises after feeding (Meier et al., 2010). In the present study, a daily rhythm of plasma NEFA was not detected with night feeding. The daily rhythmicity of AM feeding was mostly associated with increased NEFA in the overnight period, presumably due to decreased nutrient absorption during this period. The increased plasma insulin during the overnight period with evening feeding appears to have decreased lipolysis and plasma NEFA.

\section{CONCLUSIONS}

Time of feed delivery has little effect on daily intake or milk production. However, both time of feeding and feeding frequency can adjust the daily rhythms of feeding behavior, rumen function, and plasma hormones and metabolites of dairy cows. Time of feeding had a large effect on the size of conditioned meals after feeding, but only a modest effect on the pattern of spontaneous feeding at other times of day. Feeding at night increased conditioned feeding and insulin secretion after feeding and resulted in decreased plasma glucose after feeding and decreased plasma NEFA during the overnight period. Time of feeding also appeared to modify rumen function over the day.

\section{ACKNOWLEDGMENTS}

The authors gratefully acknowledge the technical assistance of Andrew Clarke, Jared Risser, Daniel Rico, Liying Ma, Kan Zhou, and Natalie Urrutia (Penn State University, University Park, PA). Gratitude is also expressed to the Pennsylvania State University Dairy Cattle Research and Education Center (University Park, PA). Supported in part by Research supported by USDA Special Grant 2009-34281-20116 [PI Harvatine], Agriculture and Food Research Initiative Competitive Grant no. 2010-65206-20723 from the USDA National Institute of Food and Agriculture (Washington, DC), and Penn State University.

\section{REFERENCES}

Ahrén, B. 2000. Autonomic regulation of islet hormone secretion-Implications for health and disease. Diabetologia 43:393-410.
Allen, M. S. 1996. Physical constraints on voluntary intake of forages by ruminants. J. Anim. Sci. 74:3063-3075.

Allen, M. S., and D. R. Mertens. 1988. Evaluating constraints on fiber digestion by rumen microbes. J. Nutr. 118:261-270.

AOAC International. 2000. Official Methods of Analysis. 17th ed. AOAC International, Arlington, VA.

Asher, G., and U. Schibler. 2011. Crosstalk between components of circadian and metabolic cycles in mammals. Cell Metab. 13:125137.

Bass, J. 2012. Circadian topology of metabolism. Nature 491:348-356.

Bourdon, L., A. Buguet, M. Cucherat, and M. W. Radomski. 1995. Use of a spreadsheet program for circadian analysis of biological/ physiological data. Aviat. Space Environ. Med. 66:787-791.

Dado, R. G., and M. S. Allen. 1993. Continuous conputer acquistion of feed and water intakes, chewing, reticular motility, and ruminal $\mathrm{pH}$ of cattle. J. Dairy Sci. 76:1589-1600.

DeVries, T. J., and M. A. G. von Keyserlingk. 2005. Time of feed delivery affects the feeding and lying patterns of dairy cows. J. Dairy Sci. 88:625-631.

DeVries, T. J., M. G. Aarnoudse, H. W. Barkema, K. E. Leslie, and M. A. G. von Keyserlingk. 2012. Associations of dairy cow behavior, barn hygiene, cow hygiene, and risk of elevated somatic cell count. J. Dairy Sci. 95:5730-5739.

DeVries, T. J., M. A. G. von Keyserlingk, and K. A. Beauchemin. 2003. Short communication: Diurnal feeding pattern of lactating dairy cows. J. Dairy Sci. 86:4079-4082.

DeVries, T. J., M. A. G. von Keyserlingk, and K. A. Beauchemin. 2005. Frequency of feed delivery affects the behavior of lactating dairy cows. J. Dairy Sci. 88:3553-3562.

Drucker, D. J. 2007. The role of gut hormones in glucose homeostasis. J. Clin. Invest. 117:24-32.

Giannetto, C., and G. Picciano. 2009b. Daily rhythms of 25 physiological variables in Bos taurus maintained under natural conditions. J. Appl. Biomedicine 7:55-61.

Harvatine, K. J., and M. S. Allen. 2006. Effects of fatty acid supplements on feed intake, and feeding and chewing behavior of lactating dairy cows. J. Dairy Sci. 89:1104-1112.

Harvatine, K. J., Y. R. Boisclair, and D. E. Bauman. 2009. Recent advances in the regulation of milk fat synthesis. Animal 3:40-54.

Hasselberg, M. J., J. McMahon, and K. Parker. 2013. The validity, reliability, and utility of the ibutton(r) for measurement of body temperature circadian rhythms in sleep/wake research. Sleep Med. 14:5-11.

Huhtanen, P., K. Kaustell, and S. Jaakkola. 1994. The use of internal markers to predict total digestibility and duodenal flow of nutrients in cattle given six different diets. Anim. Feed Sci. Technol. $48: 211-227$.

Kennedy, A. D., R. D. Bergen, T. J. Lawson, and J. A. Small. 2004. Effects of evening feeding and extended photoperiod on growth, feed efficiency, live animal carcass traits and plasma prolactin of beef heifers housed outdoors during two Manitoba winters. Can. J. Anim. Sci. 84:491-500.

Knezevic, A. 2008. Overlapping confidence intervals and statistical significance. NY State News \#73. Cornell University Statistical Consulting Unit, Ithaca, NY.

Ledgerwood, D. N., C. Winckler, and C. B. Tucker. 2010. Evaluation of data loggers, sampling intervals, and editing techniques for measuring the lying behavior of dairy cattle. J. Dairy Sci. 93:5129-5139.

Lefcourt, A. M., J. Bitman, D. L. Wood, and R. M. Akers. 1995. Circadian and ultradian rhythms of peripheral growth hormone concentrations in lactating dairy cows. Domest. Anim. Endocrinol. 12:247-256.

Lefcourt, A. M., J. B. Huntington, R. M. Akers, D. L. Wood, and J. Bitman. 1999. Circadian and ultradian rhythms of body temperature and peripheral concentrations of insulin and nitrogen in lactating dairy cows. Domest. Anim. Endocrinol. 16:41-55.

Liu, S., X.-M. Chen, T. Yoda, K. Nagashima, Y. Fukuda, and K. Kanosue. 2002. Involvement of the suprachiasmatic nucleus in body temperature modulation by food deprivation in rats. Brain Res. 929:26-36. 
Maulfair, D. D., M. Fustini, and A. J. Heinrichs. 2011. Effect of varying total mixed ration particle size on rumen digesta and fecal particle size and digestibility in lactating dairy cows. J. Dairy Sci. 94:3527-3536.

Meier, S., E. S. Kolver, G. A. Verkerk, and J. R. Roche. 2010. Effects of divergent Holstein-Friesian strain and diet on diurnal patterns of plasma metabolites and hormones. J. Dairy Res. 77:432-437.

Merl, V., A. Peters, K. M. Oltmanns, W. Kern, C. Hubold, M. Hallschmid, J. Born, H. L. Fehm, and B. Schultes. 2004. Preserved circadian rhythm of serum insulin concentration at low plasma glucose during fasting in lean and overweight humans. Metabolism 53:1449-1453.

Nikkhah, A., C. J. Furedi, A. D. Kennedy, G. H. Crow, and J. C. Plaizier. 2008. Effects of feed delivery time on feed intake, milk production, and blood metabolites of dairy cows. J. Dairy Sci. 91:4249-4260.

Nikkhah, A., C. J. Furedi, A. D. Kennedy, S. L. Scott, K. M. Wittenberg, G. H. Crow, and J. C. Plaizier. 2011. Morning vs. evening feed delivery for lactating dairy cows. Can. J. Anim. Sci 91:113-122.

Oba, M., and M. S. Allen. 2003. Effects of corn grain conservation method on feeding behavior and productivity of lactating dairy cows at two dietary starch concentrations. J. Dairy Sci. 86:174183

Piccione, G., G. Piccione, F. Grasso, F. Fazio, and A. Assenza. 2007. Influence of different schedules of feeding on daily rhythms of blood urea and ammonia concentration in cows. Biol. Rhythm Res. 38:133-139.

Raffrenato, E., and M. E. Van Amburgh. 2010. Development of a mathematical model to predict sizes and rates of digestion of a fast and slow degrading pool and an indigestible NDF fraction. Pages 52-65 in Proc. Cornell Nutr. Conf., Syracuse, NY. Dept. Anim. Sci. Cornell Univ., Ithaca, NY.

Ray, D. E., and C. B. Roubicek. 1971. Behavior of feedlot cattle during two seasons. J. Anim. Sci. 33:72-76.

Rico, D. E., and K. J. Harvatine. 2013. Induction of and recovery from milk fat depression occurs progressively in dairy cows switched between diets that differ in fiber and oil concentration. J. Dairy Sci. 96:6621-6630

Robinson, P. H., M. Gill, and J. J. Kennelly. 1997. Influence of time of feeding a protein meal on ruminal fermentation and forestomach digestion in dairy cows. J. Dairy Sci. 80:1366-1373.

Robinson, P. H., M. Gill, and J. J. Kennelly. 2002. Influence of time of feeding a protein meal on diurnal patterns of amino acids in duodenal digesta protein of lactating dairy cows. Anim. Feed Sci Technol. 97:115-121.

Rottman, L. W., Y. Ying, K. Zhou, P. A. Bartell, and K. H. Harvatine. 2014. The daily rhythm of milk synthesis is dependent on the timing of feed intake in dairy cows. Physiol. Rep. 24:e12049.

Troisi, R. J. C. C. Cowie, and M. I. Harris. 2000. Diurnal variation in fasting plasma glucose: Implications for diagnosis of diabetes in patients examined in the afternoon. J. Am. Med. Assoc. 284:3157-3159.

Van Cauter, E., J. D. Blackman, D. Roland, J. P. Spire, S. Refetoff, and K. S. Polonsky. 1991. Modulation of glucose regulation and insulin secretion by circadian rhythmicity and sleep. J. Clin. Invest. 88:934-942

Van Soest, P. J., J. B. Robertson, and B. A. Lewis. 1991. Methods for dietary fiber, neutral detergent fiber, and nonstarch polysaccharides in relation to animal nutrition. J. Dairy Sci. 74:3583-3597. 